\title{
Roadmap to Early Implementation of Passenger Air Mobility: Findings from a Delphi Study
}

\author{
Kshitija Desai $^{\dagger}$, Christelle Al Haddad ${ }^{*}+(\mathbb{D}$ and Constantinos Antoniou \\ Chair of Transportation Systems Engineering, TUM Department of Civil, Geo and Environmental Engineering, \\ Technical University of Munich, Arcisstrasse 21, 80333 Munich, Germany; kshitija.desai@rwth-aachen.de (K.D.); \\ c.antoniou@tum.de (C.A.) \\ * Correspondence: christelle.haddad@tum.de \\ t These authors contributed equally to this work.
}

check for updates

Citation: Desai, K.; Al Haddad, C.; Antoniou, C. Roadmap to the Early Implementation of Passenger Air Mobility: Findings from a Delphi Study. Sustainability 2021, 13, 10612. https://doi.org/10.3390/su131910612

Academic Editors: Maria Nadia Postorino and Chiara Caterina Ditta

Received: 10 May 2021

Accepted: 17 September 2021

Published: 24 September 2021

Publisher's Note: MDPI stays neutral with regard to jurisdictional claims in published maps and institutional affiliations.

Copyright: (c) 2021 by the authors. Licensee MDPI, Basel, Switzerland. This article is an open access article distributed under the terms and conditions of the Creative Commons Attribution (CC BY) license (https:/ / creativecommons.org/licenses/by/ $4.0 /)$.
Abstract: Urban air mobility (UAM) has recently increased in popularity as an emerging mode of transportation, covering a wide range of applications, for on-demand or scheduled operations of smaller aircraft, in and around metropolitan areas. Due to its novelty and as it has not yet been implemented, UAM research still faces uncertainties. In particular, there is a need to develop a roadmap for the early implementation of passenger air mobility, aiming to identify the most prominent challenges, opportunities, hazards, and risks, but also to highlight the most promising use cases, or on the contrary, the ones associated with the least benefits compared to the risks or complexity they entail. To answer the previous questions, and therefore address this research gap, this study used a two-round Delphi questionnaire, targeting various stakeholder groups (product owners, policymakers, researchers, consultants, investors), leading to a total of 51 experts, out of which 34 also participated in the second round. In the first round, the main challenges, opportunities, and hazards facing the implementation of passenger UAM were identified. Findings on challenges and opportunities that were dependent on use cases only (as opposed to being dependent on technology or external factors) were then fed back into the second round, which helped evaluate the use cases based both on their complexities, as well as the associated benefits. Accordingly, medical/emergency was identified as the best use case and intracity transport as the worst (in terms of complexity vs. benefits). Similarly, a risk analysis evaluated the potential hazards associated with the implementation of UAM and their impacts on the system viability. Community backlash was found to be the most hazardous one, while malicious passenger behavior and improperly designed infrastructure as the least. Findings from this study can help better understand stakeholders' opinions, highlighting promising use cases, but also risks to be aware of, constituting therefore a roadmap for future implementation.

Keywords: urban air mobility; passenger air mobility; advanced air mobility; Delphi technique; use cases; risk analysis

\section{Introduction}

Recent technological advances have facilitated the emergence of urban air mobility (UAM), the concept of using vertical takeoff and landing (VTOL) aircraft for transporting passengers within an urban area [1]. NASA defines UAM as "a safe and efficient system for air passenger and cargo transportation within an urban area, inclusive of small package delivery and other urban Unmanned Aerial Systems (UAS) services, that supports a mix of onboard/ground-piloted and increasingly autonomous operations" [2]. According to this definition, the operation of air taxis would be limited to metropolitan regions and urban areas. However, recently, commercial pilot operations of small aircraft have also emerged in areas that are not easily accessible by road transport or traditional airplanes. This is for instance the case of the startup Zipline, which offers the delivery services of medical 
supplies from distribution centers to hospitals in the rural regions of Africa [3]. Similar opportunities were observed in scenarios such as mountainous regions or islands where these small aircraft would improve the connectivity, saving on infrastructure costs and travel time. Accordingly, UAM expanded from only urban operations, to the broader term of "advanced aerial mobility" (AAM), adopted by NASA as well, which includes rural and exurban areas, as well as the more challenging urban areas, making UAM essentially a subset of AAM [4].

Research on UAM has focused on various aspects concerning its feasibility, ranging from technical perspectives, such as scaling constraints for UAM operations [5], technological barriers to the elevated future of mobility [6], considerations about airspace integration for the air mobility ecosystem [4], assessment [7] and integration with existing transport alternatives [8], but also societal aspects [9], including as well the acceptance and adoption [10], user preferences for transportation modes in a future involving UAM [11], and the identification of relevant aspects for personal air transport system integration in urban mobility modeling [12].

Similar to other emerging technologies, stakeholders in the UAM ecosystem have contrasting and independent opinions regarding the operation of UAM, as well as the challenges, benefits, and risks related to initial use cases. Understanding these perspectives is crucial to target the right use cases for an early implementation of passenger UAM, leading to possibly better adoption rates, but also economically feasible use cases. To the best of the authors' knowledge however, existing studies have not yet focused on understanding these diverging stakeholders' points of view. This paper therefore aims to close this existing gap, by specifically focusing on the early implementation of passenger urban air mobility (PAX-UAM). The aim would be to identify possible challenges, hazards, associated risks, but also benefits, pertaining to UAM implementation, in order to eventually highlight the use cases that would make the most sense to focus on.

The remainder of this paper is structured as follows. First, a literature review is presented (Section 2), giving an overview of the current findings pertaining to PAX-UAM. Then, the research methodology is given (Section 3), elaborating on the Delphi technique used. After that, the survey results are presented (Section 4) and then discussed (Section 5). Finally, the conclusion highlights the main findings of this research, along with its limitations and needs for future research (Section 6).

\section{Related Work}

\subsection{Uncertainties and Challenges}

As a new mode of transportation that is not yet implemented, UAM faces many uncertainties. Until now, there have been no real large-scale applications, apart from some trials performed in very restricted environments, such as City Airbus' first flight [13], Lilium's maiden flight in Munich [14], and Volocopter's demonstration in Stuttgart [15]. Due to numerous applications for passenger transportation, starting with the right use case could greatly shape public acceptance, but also economic returns [16]. Uncertainties also arise due to the complexity and challenges associated with UAM's implementation.

Despite technological progress and market potentials, several challenges remain and need to be considered to bring the PAX-UAM services into reality [17]. Among these challenges (or potential barriers) are community acceptance [18-22], technological challenges (including battery technology and vehicle efficiency) [17,22,23], infrastructure [5,17,20,21,23], air traffic management (ATM) [17,21,23], cost and affordability [5,17-20], certification [17,19,21], weather [19,20], pilot staffing [20] and training [17], safety and perceptions $[17,20,23]$, emissions [17], noise $[5,17,24]$, and cyber-security $[4,19]$.

\subsection{Benefits}

Previous market studies and reports claimed various benefits and opportunities for introducing UAM to the existing transportation sector. Among these is the opportunity for faster travel and reduced travel times $[25,26]$. Improving the transport system, UAM has 
also been claimed to reduce traffic congestion [19,27], reducing thereby commute travel times. This reduction in travel time was also associated with environmental benefits, due to an associated reduction of pollution $[19,27]$, but also benefits in improving road safety, due to reducing accidents resulting from lower traffic [19,27].

UAM has been seen as a mode requiring relatively low infrastructure $[25,26]$, being flexible and easy to configure. Finally, the different benefits or opportunities of UAM have been claimed to allow the introduction of additional commute options, leading to a seamless travel experience [17].

\subsection{Hazards and Risks}

While not always mentioned as hazards, previous literature highlighted possible "barriers" that could threaten the viability, which can be classified as follows:

- Technological: including various aspects of technology failures [4]. These can include powertrain, GPS/receiver failure, and problems with the autonomous systems;

- Operational: targeting the aircraft and the traffic management, especially if the integration of the UAM and the existing commercial aerospace ecosystem is not seamless [5];

- External environment: weather, collision with birds [28], tall buildings, and power lines;

- Human-related: inadequate pilot training for maintaining safety margins, loss of situational awareness and errors made by pilots [20], passenger interference in the systems, and emergency/sickness situations of the passengers;

- Cybersecurity: cyber-hacking $[4,19]$ or hijacking of the autonomous aircraft, as indicated in [29];

- Ground infrastructure: lack of vertiport availability (occupied, damaged, closed to traffic) and inadequate ground crew training for maintaining safety margins.

\subsection{Use Cases}

UAM can operate in the form of many use cases depending on the vehicle technology and market size. The use cases consolidated by the researchers for PAX-UAM include air shuttles [19] within and in between cities, on-demand air taxis [19], air ambulances [19], police surveillance, natural disaster relief services, corporate travel, and extreme sporting and amusement activities.

\section{Methodology}

\subsection{Study Setup}

Collecting expert opinion is not uncommon in transportation research, mostly when the questions investigated pertain to an inexistent mode, e.g., expert opinions were collected on the uncertainties in the implementation of mobility-as-a-service (MaaS) [30]. In the context of our study objectives, relevant expert opinion was deemed necessary in relation to the early implementation of passenger air mobility. Accordingly, this paper used a Delphi study to gather the information needed to help better understand the challenges, but also the opportunities associated with the early implementation of passenger air mobility, along with the best possible early use cases for safe and efficient operation.

The data collection was based on two rounds of questionnaires, as presented in Figure 1. The collected responses were based on anonymity, iteration, and a controlled feedback, as is common in Delphi studies [31,32]. As indicated in Figure 1, important components of the study were the selection of experts and the different rounds in the survey.

The surveys were conducted between April 2020 and July 2020, using the online survey platform LimeSurvey. The first round of the study consisted of qualitative, as well as quantitative questions. In the former, the experts were asked open-ended questions about potential challenges, opportunities, or benefits and hazards associated with UAM implementation. The quantitative part consisted of explorative questions, providing a basis for forecast related to the implementation of PAX-UAM. The qualitative questions of the 
first round were used to formulate the quantitative questions of the second round. The Delphi technique was modified such that instead of coming to a consensus, the output of the first round was fed back as an input for the second round, to better understand experts' viewpoints from the first round, but also to revalidate specific topics and perspectives.

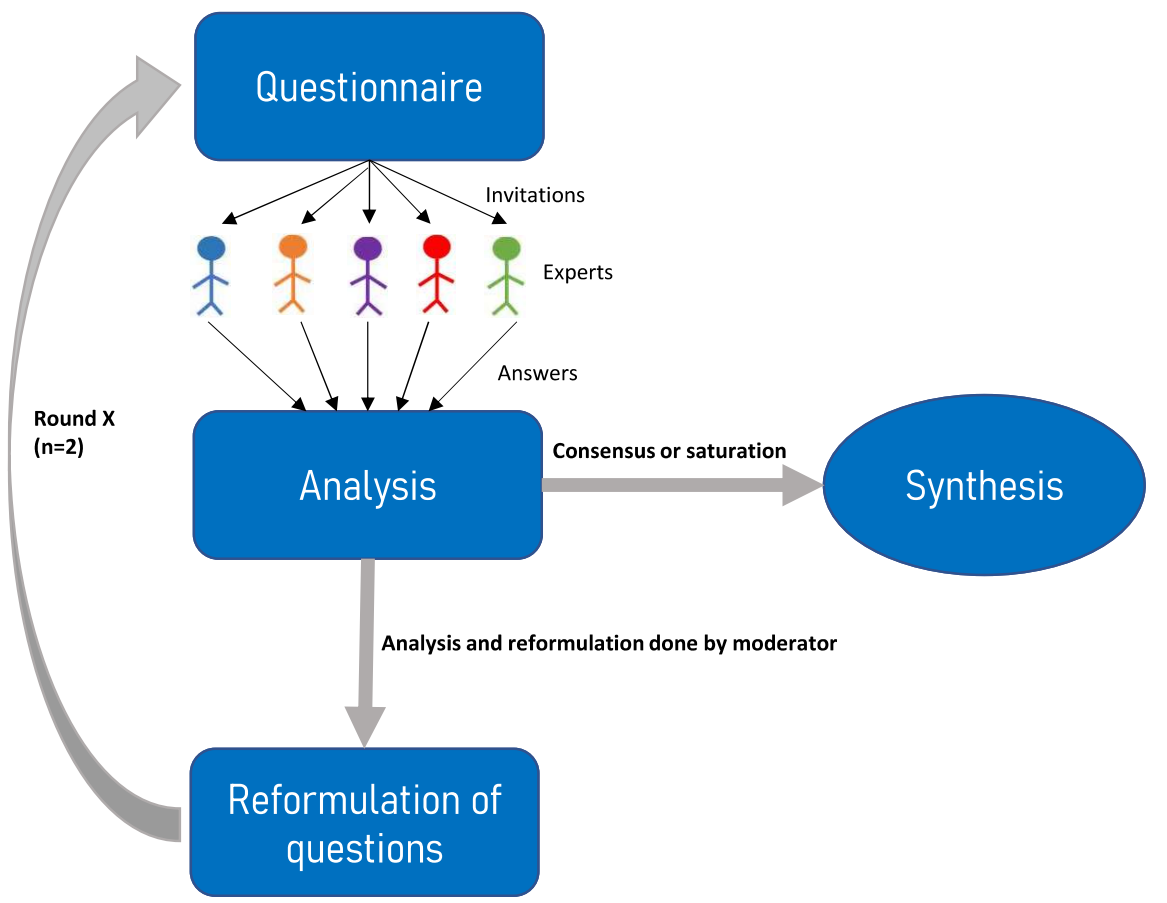

Figure 1. Data collection methodology (own illustration).

\subsection{Experts Selection}

As previously mentioned, the section of experts is a crucial step in the Delphi technique, as it ensures the quality and completeness of the process. Experts were selected in this study as follows:

- Identifying researchers and scholars working in the area of UAM and electric aviation;

- Attending conferences and online webinars, in order to shortlist speakers and panelists.

These were often consultants and investors;

- Shortlisting founders of startups including air taxi manufacturers, ATM, or electric powertrain solutions for aircraft;

- Contacting policymakers in the aviation space, for instance from EASA and FAA.

Nominated experts were then contacted via email and social network services for professionals (e.g., LinkedIn), and their consent was given for inclusion in the study. Eventually, 75 experts were invited to participate in the study, out of which 51 completed the first round. The response rate of $68 \%$ was found to be quite satisfactory compared to other studies, where the response rate ranged from $15 \%$ to over $60 \%$ [33]. In the second round, 34 experts remained (out of the 51), or a response rate of $66 \%$.

The list of nominated experts was initially strongly dominated by North American and European experts; therefore, further effort was made to ensure a better representation from other continents and regions such as Asia, Africa, the Middle east, and Australia. While still mostly from the U.S. and Europe, the remaining experts came from the U.K., South Africa, Canada, Singapore, India, the Middle East, China, and Australia.

The selected experts $(\mathrm{N}=51)$ covered various stakeholder groups including consultants, researchers, policymakers, product owners, investors, and others (journalists, pilots, supporting institutions, managers in aviation corporations). 
It is worth noting that despite the nomination of the experts and the invitation to the survey, the participation in this study was completely voluntary. The experts had full flexibility to end or withdraw their participation at any point in time.

\subsection{Survey Structure}

In the first round, the experts were given the background of the study, the area of focus, and a short introduction to the Delphi technique, a well as an estimate of the time needed to fill in the survey. The following questions were asked:

- What are the biggest challenges for the implementation of PAX-UAM?

- What opportunities do you see with the implementation of PAX-UAM?

- What are the greatest hazards during the operation of PAX-UAM?

The experts were required to write at least three answers to each of these questions. The second section consisted of exploratory multiple-choice questions regarding the general implementation aspects of PAX-UAM. After analyzing the responses from the first round, the second round was developed, focusing on possible early use cases for PAX-UAM, based on the identified opportunities and challenges.

In the second round, experts were asked to rate the identified use cases in terms of their associated challenges, but also benefits, using a five-point Likert scale [34]. Finally, in order to develop a risk assessment for the implementation of UAM, an impact-probability matrix was chosen to evaluate the hazards mentioned by the experts [35]. Accordingly, hazards mentioned in the first round were given in the second, for which experts were required to provide a rating based on the probability of occurrence of each hazard and its impact on UAM's viability.

\section{Results}

\subsection{First Round}

As mentioned in Section 3, the first round included open-ended questions and focused on topics that were deemed useful to further investigate in the second round, such as challenges, benefits, hazards, and use cases for UAM implementation. Due to the qualitative nature of most questions, similar topics or responses were often grouped, to make more comprehensive descriptions, following [33]. In the following subsections, the identified challenges, benefits, use cases, and hazards are presented. It is important to note that the explanations provided while listing these findings stemmed from a reformulation of the experts' inputs.

\subsubsection{Challenges}

The first round of surveys helped identify various challenges raised by the experts, which could hinder the early implementation of PAX-UAM, and these are presented in Figure 2.

The qualitative analysis of the open-ended questions pertaining to the challenges gave insights into how these interact with each other. According to the experts, community acceptance arose due to societal concerns such as noise, safety, affordability, fear of autonomy, range anxiety (for electric aircraft), visual pollution, privacy invasion, inequality, and "not in my backyard", also referred to as NIMBYism. Noise itself is a concern for lower altitude flights, especially during take-off and landing, and varies from region to region, along with the different levels of acceptance. When mentioning safety, experts expressed their concerns for the phase shift from hover to forward flight, which is notoriously difficult to train or safely automate, especially in the presence of air turbulence/wind gusts. Safety was also associated with costs, not only for design, but also operation. Community acceptance itself can impact UAM's viability due to the need to develop new infrastructure and regulations.

Infrastructural challenges were related to difficulties in locating skyports and constraints in building new infrastructure, the lengthy process of approvals, the management of the electric grid for new skyports, and the management of the airspace around skyports. After that, regulatory challenges were listed, stemming from the fact that there is not yet a 
regulatory framework for UAM certification, pilot licensing, the operation of autonomous air vehicles, ground, infrastructure, noise for urban operations, air traffic management (ATM), insurance, etc. This creates a challenge for the designers because they do not have a standard to use as a guide for certification, and on the other hand, the biggest challenge is that the regulatory framework to certify these vehicles does not yet exist.

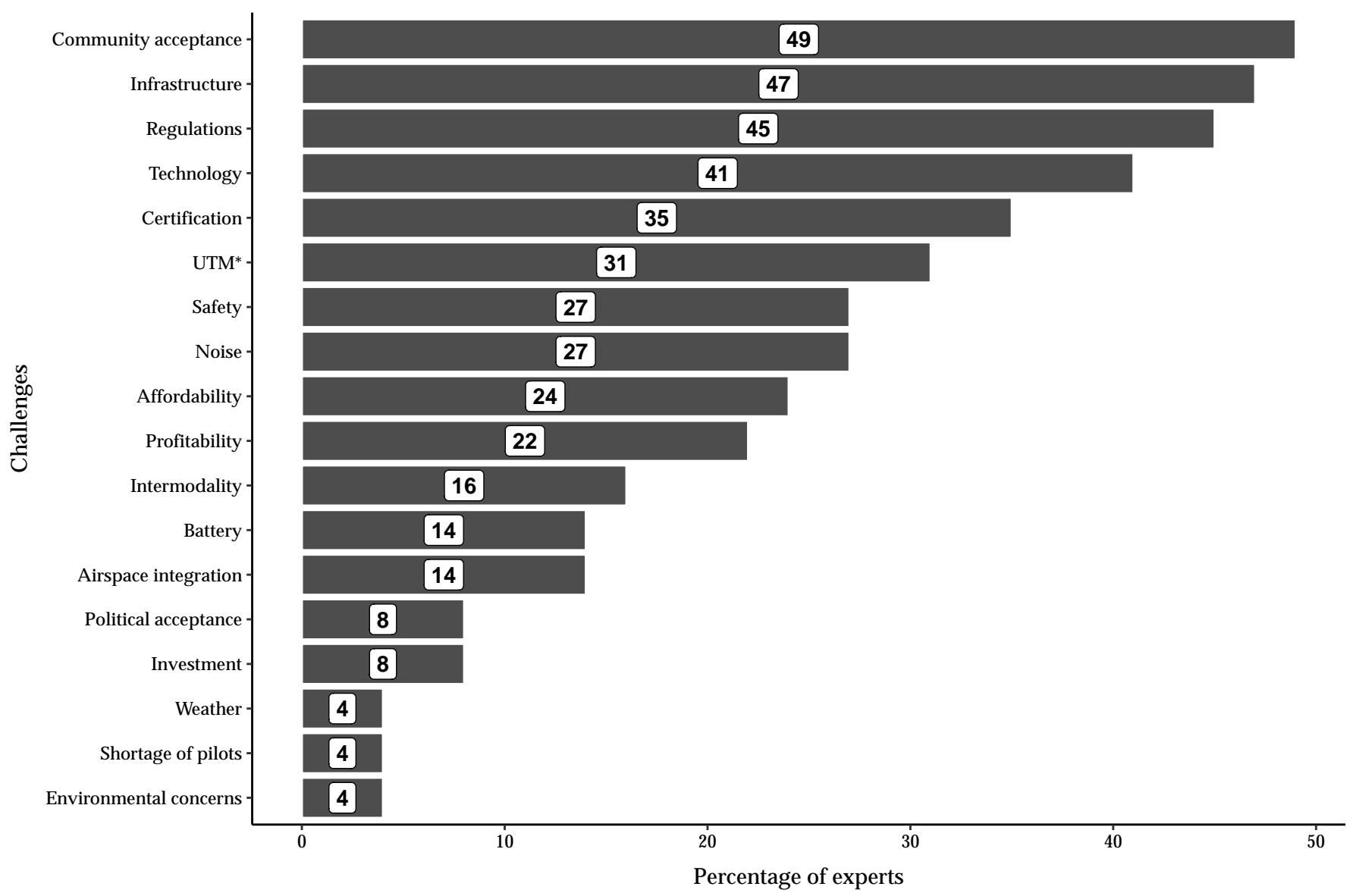

Figure 2. Identified challenges based on the analysis of Round $1(\mathrm{~N}=51)$. Unmanned aircraft system traffic management.

Technological challenges were then mentioned and classified into three main categories: battery, airworthiness, and automation. Current battery technologies are limited to short distances due to the battery energy density. PAX-UAM designs rely on advancement in batteries for a better range, and the battery endurance and recharge rates will impact initial aircraft turnaround times and operational route planning as well. Automation is necessary for safe operations of the aircraft, as it is supposed to reduce or remove human error and make the business more profitable. Developing a new system in the airspace for the operations of PAX-UAM that can accommodate the proposed levels of PAX-UAM traffic is a challenge. As the certification of air taxis would be associated with high costs, the returns would be expected from the services provided by them to the public. Profitability and economic viability would then go against affordability for users, which itself is key for acceptance. Moreover, the process of developing an aircraft and certifying it for commercial operation is an extremely long-term proposition, much longer than most investors are willing to wait for, which in turn would explain the lack of investment (both private and public). This creates a barrier for the aircraft manufacturing companies to move ahead in terms of tackling other challenges.

Political acceptance itself can be a challenge, unless UAM proves to be a form of transport with benefits to residents and industries, but not a public nuisance. Intermodality in that aspect could help UAM be integrated with other modes of transport, so that UAM 
travels would be seamless and save time. This however could be challenging, as it would involve locating skyports with other transportation hubs such as light rail stations. Further concerns included UTM, airspace integration, the shortage of pilots, and environmental concerns. Finally, unpredictable weather conditions could be threatening for operating PAX-UAM, for instance during turbulent weather, mentioned as a challenge by the experts, mostly for UAM stability.

\subsubsection{Benefits}

The identified benefits to UAM implementation mentioned by the experts can be categorized under: provision of higher quality of life to the public, economic gains, reduction of environmental impact, and provision of a path to a new technology, as listed in Figure 3. A detailed analysis of each of these benefits, as expressed by the experts, is detailed in the paragraphs to follow.

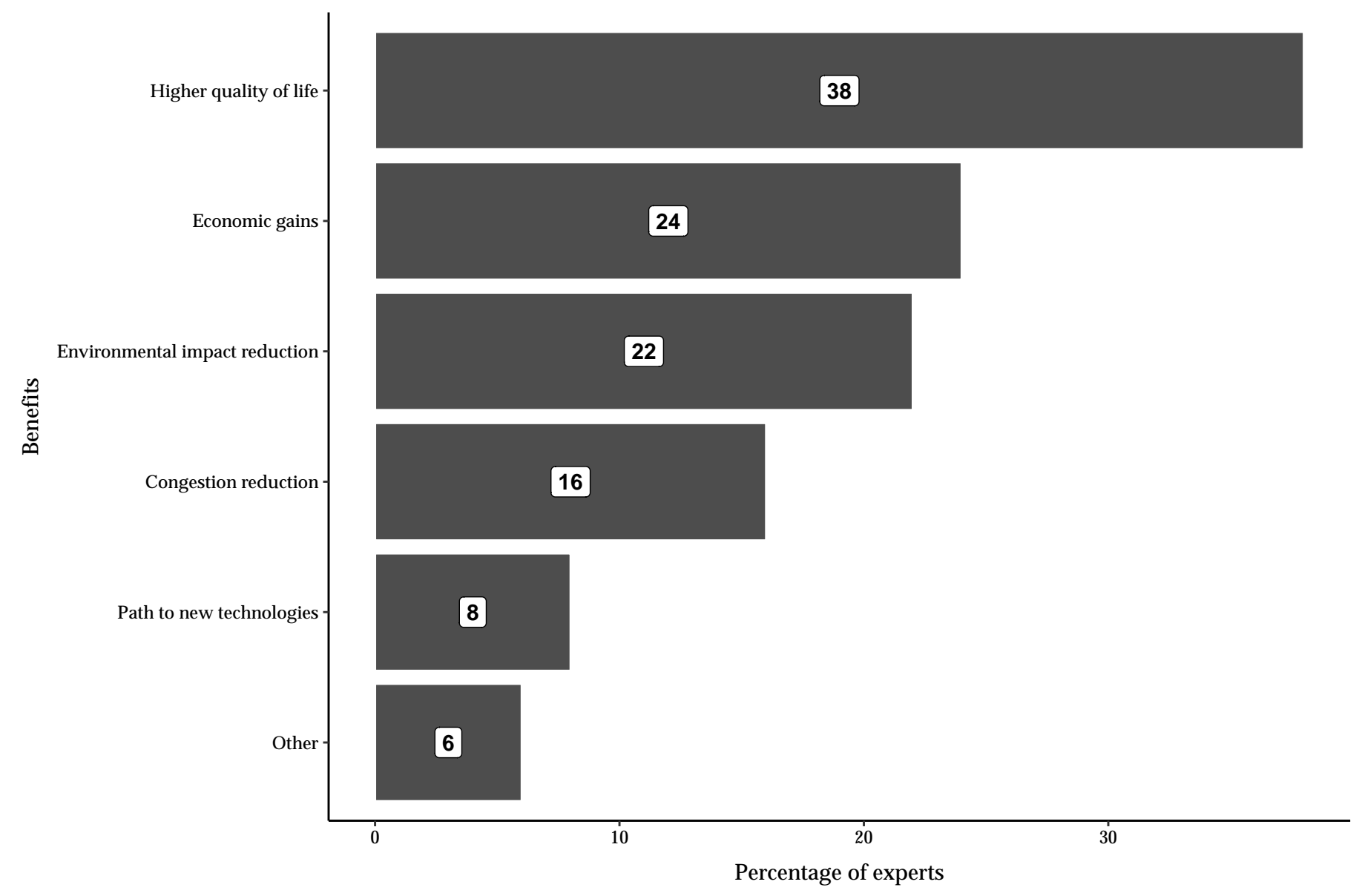

Figure 3. Identified benefits based on the analysis of Round $1(\mathrm{~N}=51)$.

PAX-UAM would benefit the public and would have the potential in improving the quality of life of the people in and around the metropolitan areas with factors such as time savings and better utilization of space for recreation due to a lower need for infrastructure. Time savings also indirectly leads to economic benefits. This form of transportation could also replace some of the private transportation means, enabling cities to rethink their development and to convert some streets into green spaces. It would open new approaches and ideas on how to plan, design, and develop future cities. Further, UAM could provide an additional mode of transport to the public.

This emerging mode of transport would potentially give birth to a new transportation sector by reviving the small aircraft industry. It would open doors for businesses, not only to the players, but also to a new secondary market in support of UAM transport 
such as design consultation services and the development and registration of different parts of the ecosystem such as ATM and vertiports. It would overall lead to increased economic opportunities such as expanding the labor and trade market. Furthermore, by using electrically powered aircraft, PAX-UAM would offer an opportunity to reduce carbon emissions in urban and suburban areas (depending on the method of electrical power generation). PAX-UAM could potentially represent a greener, quieter, and safer alternative to helicopters without limiting transportation means.

Finally, the PAX-UAM industry could provide a platform to mature the electrification in the aviation industry. By addressing the safety concerns of the existing air transport services, a new certification standard can be developed. This would provide an opportunity to leverage lessons learned from modern system design and computer-based development of systems, algorithms, machine learning, etc. The technology available today from the self-driving car and industrial automation markets may assist the development of new capabilities for software, hardware, verification, validation, testing, production, etc., for advanced air mobility concepts.

\subsubsection{Use Cases}

Experts listed the following use cases as the most suitable ones for early operations of PAX-UAM.

- $\quad$ Emergency or medical services: this includes transportation for medical emergencies (air ambulance), delivery of critical supplies, organ transport, and fire brigade services;

- Connection to remote locations: this could improve mobility and access to remote and underserved areas that may otherwise not have good access to surface transportation or regions where passenger volumes do not justify building new roads or train lines;

- Intercity transport: to increase connectivity between city centers and central business districts directly across regions; this could be particularly relevant where two cities are obstructed by mountains or other terrains, which could be overcome by PAX-UAM services without heavy infrastructure;

- Intracity transport: this could provide fast transportation for cities with consistent traffic jams, i.e., where it would take longer than several hours to cover distances within $30 \mathrm{~km}$ of range due to traffic. Volocopter for example is working on the use case of transportation services within cities [28];

- Fun/adventure: PAX-UAM could provide the experience of flying to people. This use case is also being considered by Ehang in China [27];

- $\quad$ Airport shuttle services: airports are usually located outside the city, with access usually impeded by traffic. PAX-UAM could potentially offer services from a hub in the city center to the airport. Urban hotels in the city center could accommodate such services directly from the hotel to the airport;

- Defense applications (It is important to note that while defense applications do not fall under passenger air transportation (the focus of this paper), this has been kept for the remainder of the paper, as (i) it was spontaneously provided by (some of) the experts and (ii) due to the interesting insights provided by the experts on, but not limited to, this application): although this is currently not seen as the most desirable target by many manufacturers, defense application is likely to be one of the initial applications, especially for the e-VTOLs design [36]. The main advantage of this use case is that certification is not required. This use case can include: rescue operations and transportation of essential and specific assets, police surveillance, and reconnaissance;

- High-speed transport for high-income individuals: PAX-UAM service for business persons can offer a cleaner and greener mode of transport for long business trips in comparison to private cars. This use case was also discussed in [11];

- Cargo applications (This is also not a typical passenger air mobility use case, but was kept for the purpose of reporting the experts' viewpoints): this becomes the most affordable method of moving parcels around metro areas; 
- Agriculture use: an agricultural tool for spraying pesticides or insecticides over the fields (however also not pertaining to passenger air mobility);

- Replacement of helicopters.

\subsubsection{Hazards and Risk Assessment}

Potential hazards pertaining to the implementation of UAM were grouped under various categories, based on the experts' viewpoints, and are summarized in Figure 4.

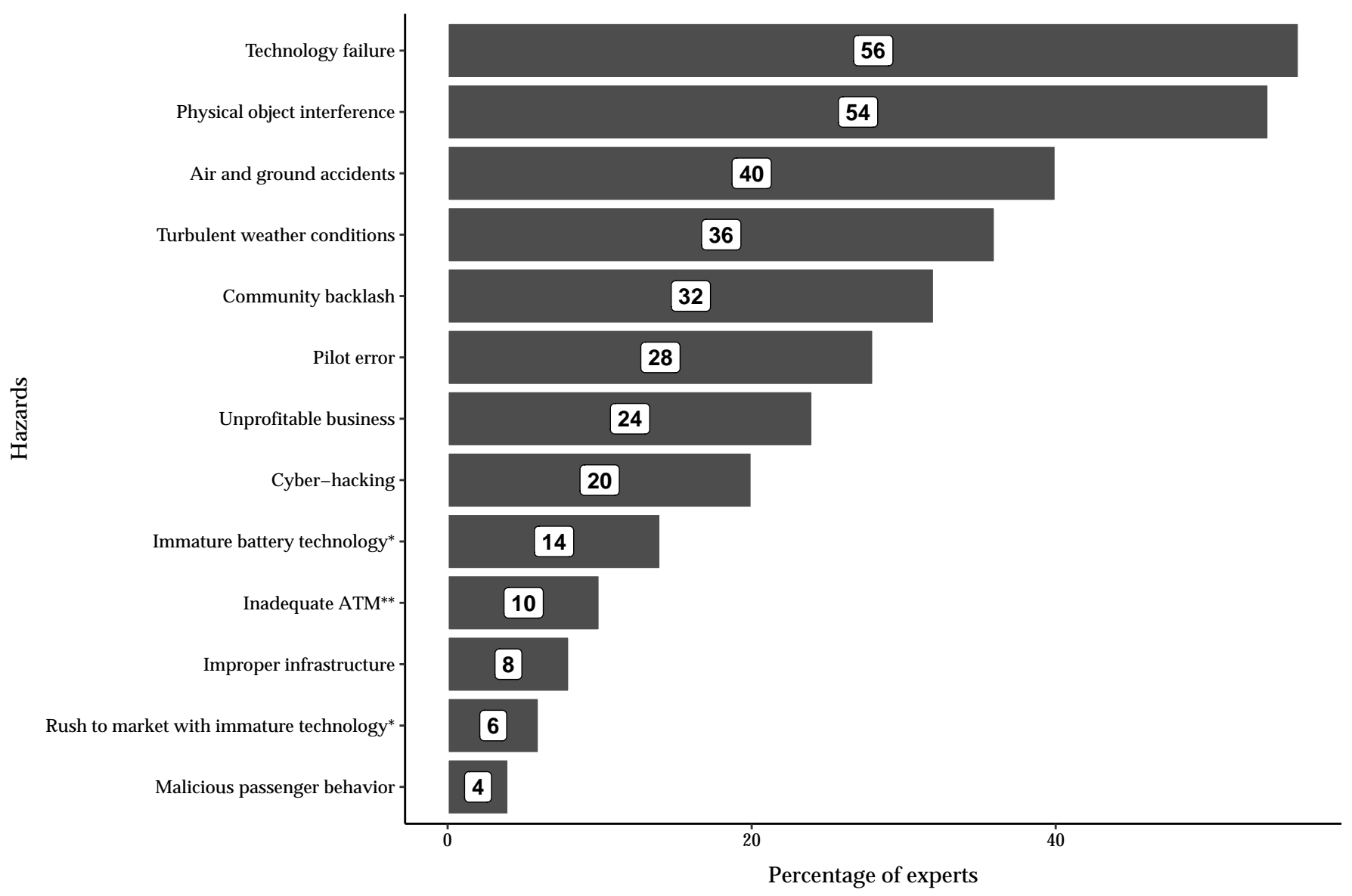

Figure 4. Identified hazards based on the analysis of Round $1(\mathrm{~N}=51)$. ${ }^{*}$ Both hazards pertaining to technology (immature battery technology or rush to market) could be bundled up, but were not since (i) they would still lead to $20 \%$, which is still not larger than cyber-hacking and (ii) the aim was to present findings as close as possible to the ones reported by the experts. ** Air traffic management.

Technological failures can lead to crashes due to the malfunctioning of onboard subsystems of the aircraft, including propulsion, flight control system, communications, etc. Experts listed many possible failures, such as the malfunctioning of ground systems such as radar, communications, air-collision-detection systems, the absence of high-fidelity weather radar from the ground level to a couple of thousand feet, unforeseen software issues that could compromise vehicle airworthiness, the loss of navigation, the loss of the control of operation, onboard system failures, and the failure of electrical power systems, especially for multirotor and thrust-vectoring configurations. As most e-VTOL designs do not have the ability to glide or autorotate, parachutes may become necessary; however, these are less effective at low altitude and may not mitigate the risks. Additionally, electrical power systems are not as mature and may develop unpredictable faults, especially due to the lack of established maintenance procedures. Furthermore, the removal of humans from the management of the flight operations, together with an increased system criticality 
could be a lethal combination. Further challenges could be operational, such as inadequate maintenance procedures, poorly defined passenger loading procedures, etc.

Batteries can be considered as by far the weakest link in the system. Batteries are prone to runaways, inexplicable failures, erroneous state-of-charge readings, and fires, which could lead to unexpected hazardous situations. A rush to enter the UAM market might be a threat on its own, in case the technology has not reached the desired level of maturity. Infrastructure as well plays a major role in the successful implementation of UAM. Poorly designed infrastructure could lead to detrimental consequences. For instance, a collapsing pod on a building roof, or mechanical failures, or passenger health or security issues are likely to occupy or obstruct a specific skyport as a landing site for other aircraft, which would overburden other landing sites, straining thereby not only the air network, but also the other modes of transportation.

Physical interference with objects in the air could include misidentification of the surroundings or the loss of connection by the detect and avoid systems, which can lead to interference or collisions and eventually accidents in the air. Bird networks and man-made objects can be expected on roofs and sides of buildings; for instance, moving construction cranes and "dead" communication spots can cause disturbances during a flight. A lack of interoperability standards that can guide flight operations with cooperative ATM architectures could also result in collisions during the flight.

In the case of early safety incidents, but also due to environmental impacts and a lower accessibility to the mass market, community acceptance could be hindered, limiting the use of PAX-UAM. Even if national governments maintain regulatory control over the airspace and despite communities accepting the concept initially, they could decide not to allow the further construction of vertiports and/or make vertiport regulations/zoning so onerous that they effectively limit/ban PAX-UAM.

A further potential hazard could be witnessed due to human errors, such as the ones resulting from pilots, as well as passengers during the flight. Such human failure would increase significantly with an increased frequency of operation in urban environments. Insufficiently trained pilots may lead to automation failure or human-automation interaction failure. Passengers themselves could also become a threat to operation, when engaging in malicious behavior onboard. Proper education and security checks must therefore be an important aspect of boarding the passengers. Finally, unprofitable business can be seen as well as a potential hazard, which could happen if the demand for PAX-UAM flights does not rise to the levels required to make business models work or if the whole setup does not become economically viable, which in turn would impact investments in UAM.

\subsection{Second Round}

In the second round, the consolidated challenges, opportunities, and hazards were given as the input to the experts to score them based on a five-point Likert scale. Challenges were accordingly classified into three categories:

- Dependent on technology: safety, noise, certification, autonomy, airworthiness, battery density, and unmanned aircraft system management (UTM);

- Dependent on the use case: community acceptance, affordability, political acceptance, intermodality, regulatory, and infrastructure requirements;

- External factors: shortage of pilots, lack of investment, inaccessible talent, sustainability/environmental concerns, and optimism bias.

Similarly, benefits were categorized as useful to assess the use cases (economic gains, higher quality of life), independent of use cases (a new technological revolution, reduction of environmental impact), or contradictory based on the experts' views (reduction of congestion).

Only challenges and opportunities dependent on the use cases were used in the second survey round. Accordingly, the use-case-dependent challenges were: community acceptance, affordability, political acceptance, intermodality and intramodality, regulatory, 
and infrastructural. The opportunities dependent on the use cases were economic gains and higher quality of life offered.

Eight use cases were chosen for the further study including airport shuttles, business transport, connection to suburbs, defense application, fun/adventure, intercity transport for public, intracity transport for the public, and medical/emergency services.

\subsubsection{Complexity of the Use Cases}

As seen in the section above, the first round enlisted several potential challenges for early operations of PAX-UAM. The complexity for various use cases was evaluated based on these challenges, and the experts were asked in the second round to rank for each of the eight identified use cases the severity of the five challenges, on a scale from one to five, where one was the least severe and five the most severe challenge. The results were then averaged out and are provided in Figure 5.

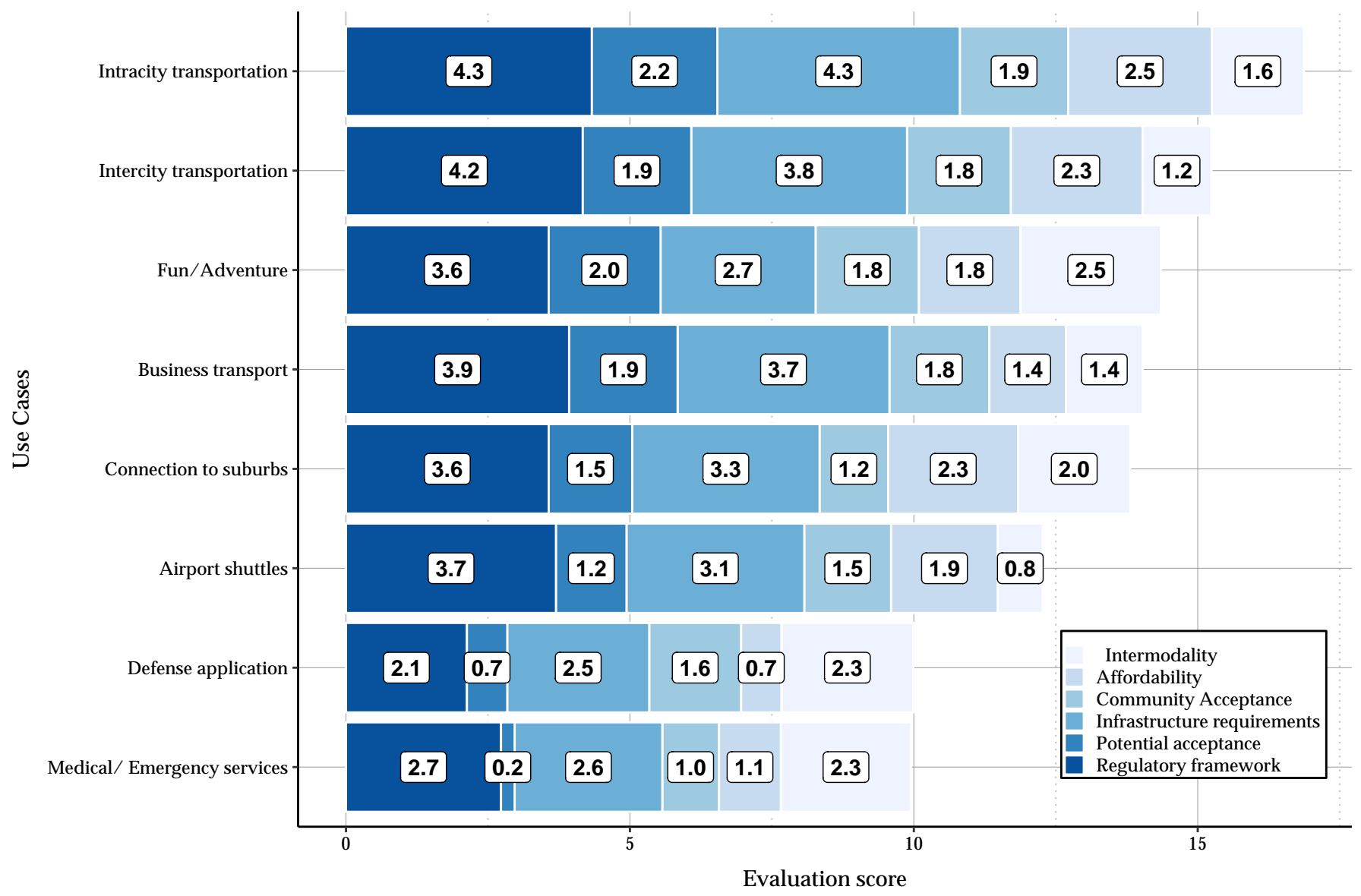

Figure 5. Complexity for different use cases.

\subsubsection{Benefits of the Use Cases}

To assess the benefits of the selected use cases, respondents in the second round were asked to rank for each use case the potential benefit (economic, quality of life) on a scale from one to five, where one is the lowest benefit and five the highest. For the economic benefit, response answers went from very low profitability to very high profitability, whereas for the impact on the quality of life, responses went from very low impact to very high impact. The assessment of benefits for the selected use cases is presented in Figure 6, for both the economic gain and provision of a better quality of life. 


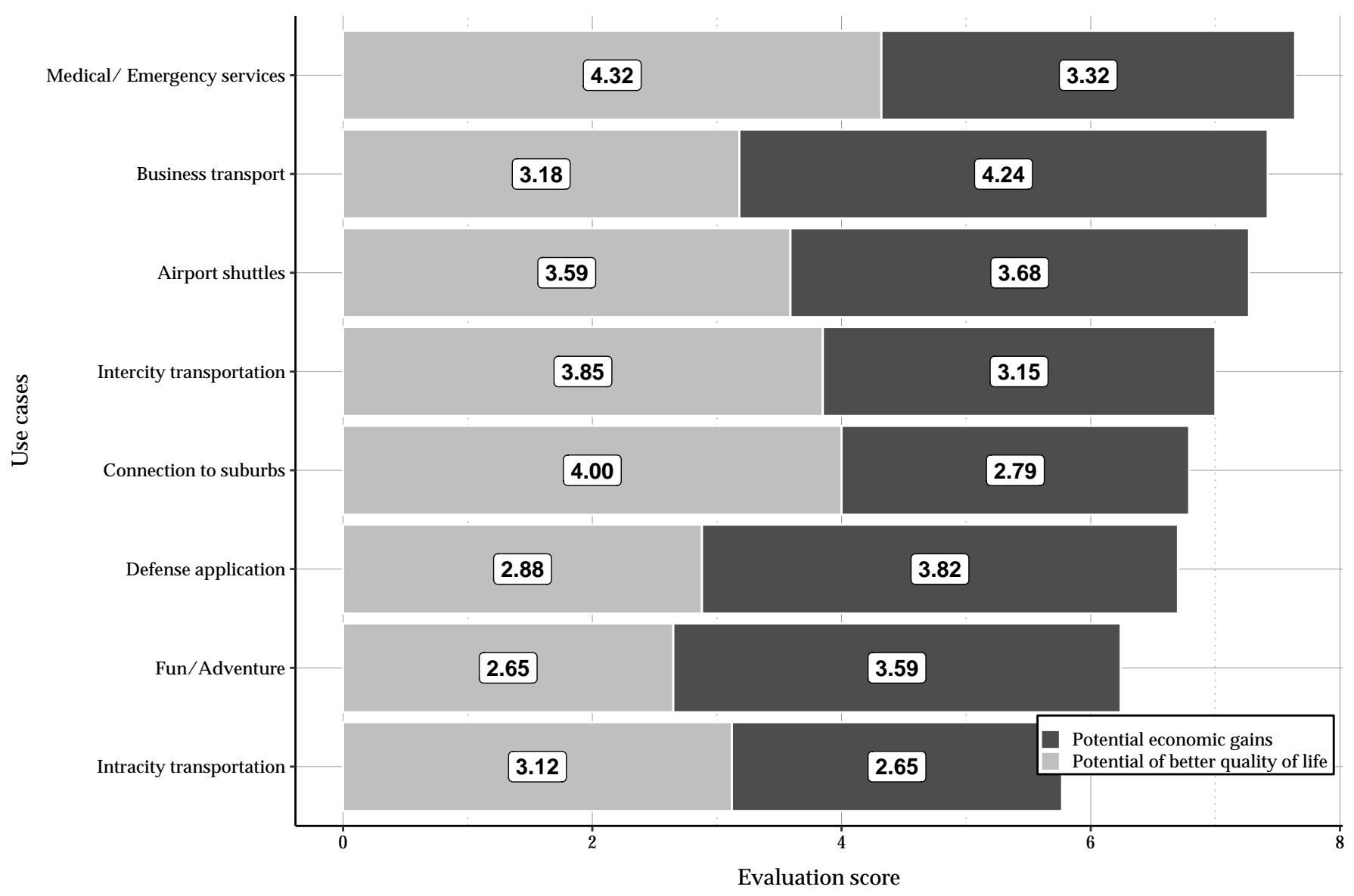

Figure 6. Benefits for different use cases.

\section{Discussion}

\subsection{Identified Gaps}

From the first round of survey, an interdependency among the regulatory framework, investments, certifications, and technological developments was identified. The qualitative analysis of the challenges highlighted the criticality of setting up the regulatory framework for the operation of UAM, for the different use cases. Regulatory challenges are complex and time-consuming, which might hinder venture capital. At the same time, certifications require large investments. However, due to the lack of adequate guidelines, there is a higher uncertainty about the investment returns, but also a further hurdle for the designs, which do not have a set of guidelines to follow.

A further gap identified was between the industry requirement and the community expectation. The first round of survey highlighted the impact of having pilots onboard for the community acceptance. A case study on the Dallas-Fort Worth area showed that a higher percentage of the respondents indicated that they would not prefer to board the automated/non-piloted aircraft [20]. Another study also showed similar results, whereby public acceptance of UAM was found to be negatively affected by remote pilots/operators, as compared to having pilots onboard [37].

Previous research on the adoption and use of urban air mobility has also mentioned trust and safety as major components behind the acceptance of fully automated aerial vehicles. Having in-vehicle cameras and operators can be helpful o increase the adoption of urban air mobility services [10]. However, having pilots onboard would increase service costs, decreasing thereby acceptance again, as the latter greatly depends on affordability. 


\subsection{Use Cases' Assessment}

The selected use cases were analyzed critically in terms of the identified challenges (Section 4.2.1) and benefits (Section 4.2.2). The weighted average method was used to evaluate the challenge score (complexity) and the benefit score (anticipated benefit) for each use case. The outcome of this analysis is presented in Figure 7 below.

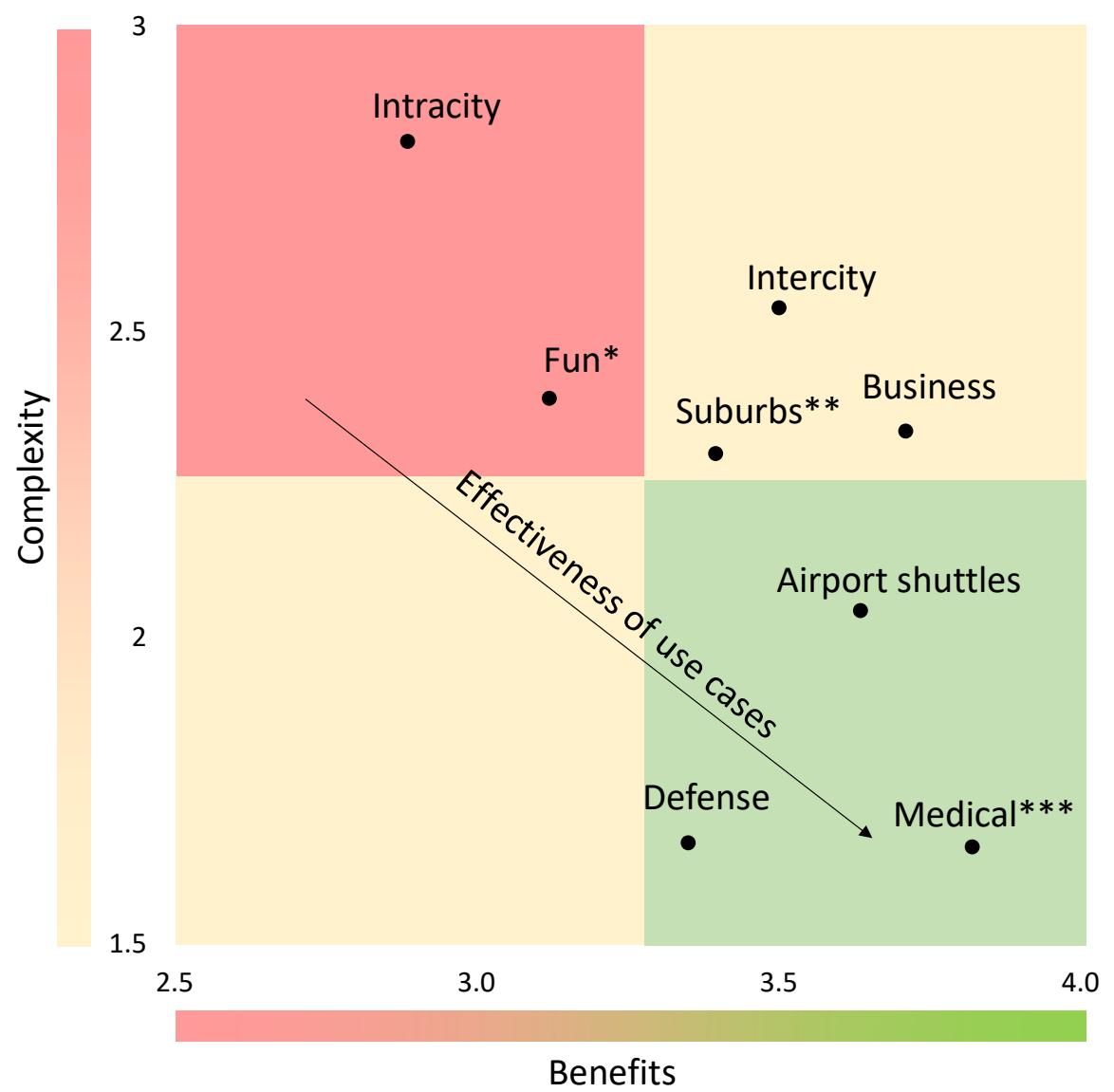

Figure 7. Use cases' assessment for PAX-UAM, in terms of complexity and anticipated benefits. * Fun or adventure. ${ }^{* *}$ Connection to suburbs. ${ }^{* *}$ Medical or emergency services.

It can be observed that the PAX-UAM use cases of medical/emergency services, defense applications, and airport shuttle services lie in the region of low complexity and high benefits and could possibly be the best for the early implementation of PAXUAM. These use cases are followed by business transport, connection to the suburbs, and fun/adventure flights, which seem to have a low complexity and medium benefits. Intercity transport services would also be beneficial for citizens, but would be associated with overall higher complexities than the use cases mentioned above. Intracity transport within metropolitan cities seems to be associated with the most complexity, but least benefits for citizens.

\subsection{Risk Assessment}

In the second round, experts assessed the hazards and risks identified in the first round. Each hazard was scored based on its probability of occurrence, but also its impact on the system's viability. Scores were also given on a five-point Likert scale and were then averaged. The risk assessment of the challenges is shown in Figure 8 below. 


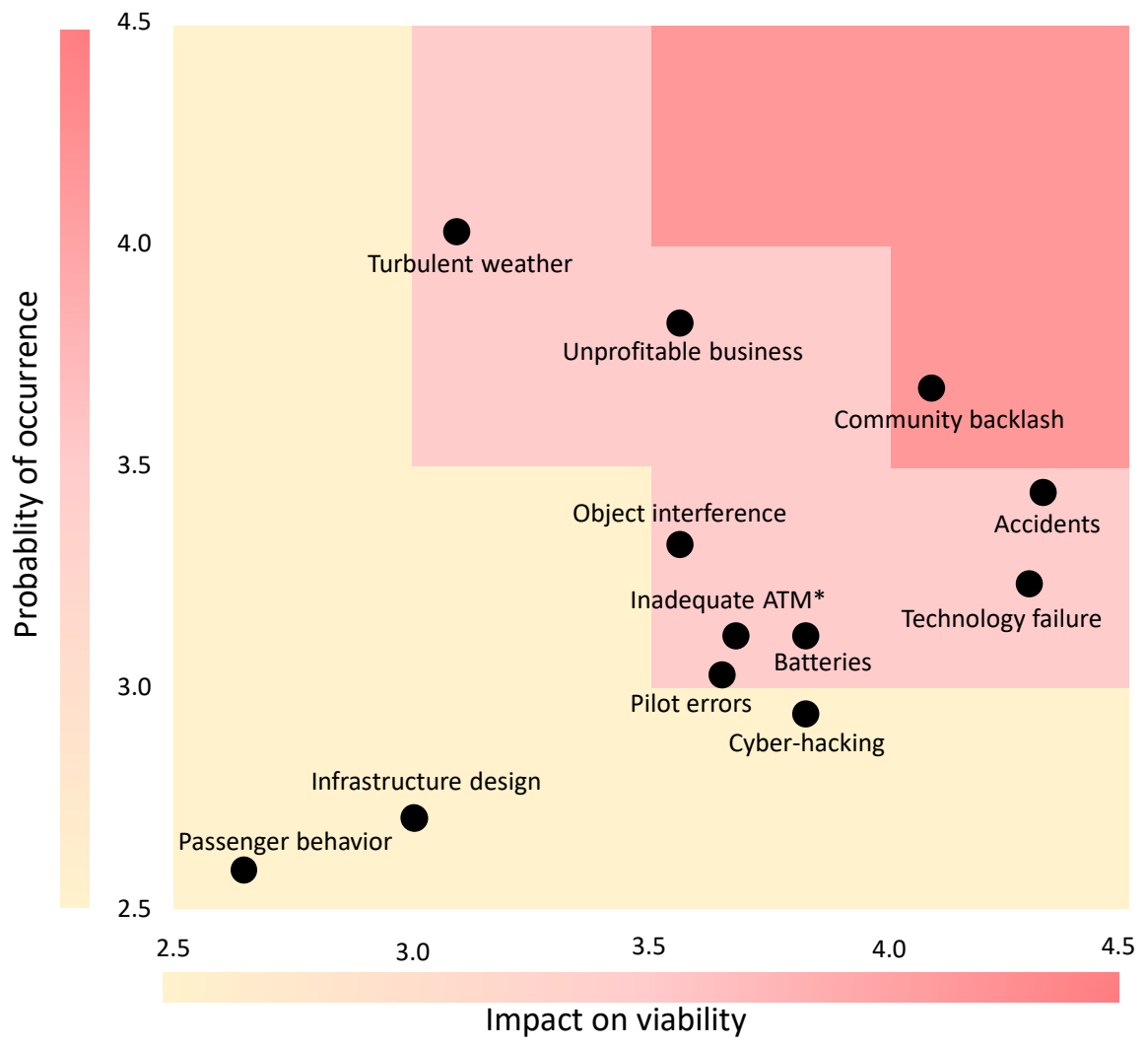

Figure 8. Risk assessment for PAX-UAM. * ATM: air traffic management.

The above matrix shows the risk assessment of the different hazards reported by the experts. The hazards can be categorized as follows:

- Very-high-risk zone: namely, community backlash. This is also one the greatest challenges in the implementation of PAX-UAM services;

- High risk zone: this includes unexpected technology failures, problems with batteries, errors by pilots, inadequate air traffic management, interference with physical objects in the air, accidents on the ground and in the air, an unprofitable business, and the hazard of turbulent weather conditions;

- Medium risk zone: this includes cyber-hacking, improperly designed infrastructure, and the malicious behavior of passengers.

\section{Conclusions}

This study provided the results of a Delphi study that collected experts' opinions on passenger urban air mobility implementation. Experts covered different stakeholder groups, including product owners, policymakers, researchers, investors, consultants, etc. The data were collected in two rounds, with 51 experts in the first and 34 in the second (due to drop-out). A qualitative analysis of the open-ended questions led to an extraction of potential challenges, hazards, and risks associated with PAX-UAM, but also potential use cases. In the second round, the inputs from the first round were given back to the experts, in order to obtain feedback on their use case assessment, on the one hand, and risk assessment, on the other. Findings revealed that medical, airport shuttles, and defense (although not pertaining to PAX-UAM) use cases were found to be the most promising in terms of benefits and complexity, while the intracity and leisure (fun/adventure) use cases seemed to be the most complex with the lowest anticipated benefits. In terms of risks, community backlash was found to be the highest hazard, in terms of its chance of occurrence and the impact on the system's viability. 
The study however does not come without limitations. The selected experts were rather concentrated in the area of the United States and Europe, and stakeholder groups could have been better represented, which might have led to biases in the responses. Moreover, the drop-out rate from the first round (51 experts) to the second round (34 experts), while consistent with previous studies, could still have affected the consensus and therefore the results. Another point is that stakeholders' viewpoints were weighted equally, when taking into account the different rates given in Round 2, which might have led to an over-representation of a specific stakeholder group.

Future work could focus on overcoming the limitations of this study by having a better represented panel of experts, in terms of expertise and geographical region. Moreover, future work could also focus on not only identifying the challenges and threats, but also working around the ways of mitigating them. A more quantitative approach including a general population survey with similar questions can complement this study to understand the perspective of users in comparison with that of the experts. Finally, while the results of this study provide a roadmap to the early implementation of passenger air mobility, this work could be extended to the cargo industry or, on the contrary, specialized, to investigate the use cases of interest, which were highlighted by this study.

Author Contributions: Conceptualization, C.A.H. and K.D.; methodology, C.A.H. and K.D.; formal analysis, C.A.H. and K.D.; writing—original draft preparation, C.A.H. and K.D.; writing-review and editing, C.A.H. and C.A.; supervision, C.A.H. and C.A. All authors have read and agreed to the published version of the manuscript.

Funding: This work was supported by the Technical University of Munich within the Open Access Publishing Funding Program.

Institutional Review Board Statement: Not applicable.

Informed Consent Statement: Not applicable.

Data Availability Statement: The data are not publicly available due to privacy reasons and according to the consent given by the experts.

Acknowledgments: The authors would like to express sincere gratitude to the experts who took the time to participate in the study, whose insights were extremely valuable for the findings highlighted.

Conflicts of Interest: The authors declare that they have no conflict of interest.

\section{Abbreviations}

The following abbreviations are used in this manuscript:

$\begin{array}{ll}\text { AAM } & \text { Advanced air mobility } \\ \text { ATM } & \text { Air traffic management } \\ \text { EASA } & \text { European Union Aviation Safety Agency } \\ \text { e-VTOL } & \text { Electrical vertical takeoff and landing airplane } \\ \text { FAA } & \text { Federal Aviation Administration } \\ \text { NASA } & \text { National Aeronautics and Space Administration } \\ \text { PAX-UAM } & \text { Passenger UAM } \\ \text { UAM } & \text { Urban air mobility } \\ \text { UTM } & \text { Unmanned aircraft system traffic management } \\ \text { VTOL } & \text { Vertical takeoff and landing }\end{array}$

\section{References}

1. Rothfeld, R.; Straubinger, A.; Fu, M.; Al Haddad, C.; Antoniou, C. Urban air mobility. In Demand for Emerging Transportation Systems; Elsevier: Amsterdam, The Netherlands, 2020; pp. 267-284. Available online: https:/ /www.sciencedirect.com/science/ article/pii/B9780128150184000139?via\%3Dihub (accessed on 20 July 2021).

2. NASA. NASA Embraces Urban Air Mobility, Calls for Market Study. 2017. Available online: https://www.nasa.gov/aero/nasaembraces-urban-air-mobility (accessed on 20 July 2021).

3. Bright, J. Zipline Begins US Medical Delivery with Drone Program Honed in Africa. 2020. Available online: https:/ / techcrunch. com/2020/05/26/zipline-begins-us-medical-delivery-with-uav-program-honed-in-africa/ (accessed on 20 July 2021). 
4. Thipphavong, D.P.; Apaza, R.D.; Barmore, B.E.; Battiste, V.; Burian, B.K.; Dao, Q.V. Urban Air Mobility Airspace Integration Concepts and Considerations. In Proceedings of the Aviation Technology, Integration, and Operations Conference, Atlanta, GA, USA, 25-29 June 2018; p. 3676.

5. Vascik, P.D.; Hansman, R.J. Scaling Constraints for Urban Air Mobility Operations: Air Traffic Control, Ground Infrastructure, and Noise. In Proceedings of the 2018 Aviation Technology, Integration, and Operations Conference, Atlanta, GA, USA, 25-29 June 2018; MIT International Center for Air Transportation (ICAT), Department of Aeronautics \& Astronautics, Massachusetts Institute of Technology, American Institute of Aeronautics and Astronautics: Reston, VA, USA, 2018. Available online: https: / / arc.aiaa.org/doi/10.2514/6.2018-3849 (accessed on 20 July 2021).

6. Lineberger, R.; Hussain, A.; Rutgers, V.; Hanley, T. Technological Barriers to the Elevated Future of Mobility. Report, Deloitte. 2019. Available online: https://www2.deloitte.com/content/dam/insights/us/articles/5098_tech-barriers-fom/DI_Techbarriers-elevated-FoM.pdf (accessed on 20 July 2021).

7. Al Haddad, C.; Fu, M.; Straubinger, A.; Plötner, K.; Antoniou, C. Choosing Suitable Indicators for the Assessment of Urban Air Mobility: A Case Study of Upper Bavaria, Germany. Eur. J. Transp. Infrastruct. Res. 2020, 20, $214-232$.

8. Ploetner, K.; Al Haddad, C.; Antoniou, C.; Frank, F.; Fu, M.; Kabel, S.; Llorca, C.; Moeckel, R.; Moreno, A.; Pukhova, A.; et al. Long-term application potential of urban air mobility complementing public transport: An upper Bavaria example. CEAS Aeronaut. J. 2020, 11, 991-1007. [CrossRef] [PubMed]

9. Shaheen, S.; Cohen, A. Shared Micromoblity Policy Toolkit: Docked and Dockless Bike and Scooter Sharing. 2019. Available online: https:/ / escholarship.org/uc/item/00k897b5 (accessed on 20 July 2021).

10. Al Haddad, C.; Chaniotakis, E.; Straubinger, A.; Plötner, K.; Antoniou, C. Factors affecting the adoption and use of urban air mobility. Transp. Res. Part A Policy Pract. 2020, 132, 696-712. [CrossRef]

11. Fu, M.; Rothfeld, R.; Antoniou, C. Exploring Preferences for Transportation Modes in an Urban Air Mobility Environment: Munich Case Study. Transp. Res. Rec. 2019, 2673, 427-442. [CrossRef]

12. Straubinger, A.; Rothfeld, R. Identification of Relevant Aspects for Personal Air Transport System Integration in Urban Mobility Modelling. In Proceedings of the TRA 2018, Vienna, Austria, 16-19 April 2018.

13. Parsons, D. City Airbus eVTOL Prototype Makes First Flight in Germany. 2019. Available online: https://www.aviationtoday. com/2019/05/06/ city-airbus-evtol-prototype-makes-first-flight-germany/ (accessed on 20 July 2021).

14. Pope, S. First Flight of Lilium Prototype Shows the Promise of Electric Air-Taxi Concept. 2019. Available online: https: / / www.flyingmag.com/lilium-prototype-first-flight/ (accessed on 20 July 2021).

15. Lambert, F. Watch All-Electric Air Taxi ‘Volocopter' Make Debut Urban Flight in Stuttgart. 2019. Available online: https: / / electrek.co/2019/09/16/electric-air-taxi-volocopter-flght-video/ (accessed on 20 July 2021).

16. Kite-Powell, J. There's No Single Best Air Taxi Concept and Here's Why. 2019. Available online: https://www.forbes.com/sites/ jenniferhicks/2019/06/05/theres-no-single-best-air-taxi-concept-and-heres-why/\#24c4b28a242c (accessed on 20 July 2021).

17. Holden, J.; Goel, N. Fast-forwarding to the Future of On-Demand, Urban Air Transportation. Technical Report. 2018. Available online: https: / / www.uber.com/elevate.pdf (accessed on 20 July 2021).

18. Baur, D.S.; Schickram, D.S.; Homulenko, A.; Martinez, N.; Dyskin, A. Urban Air Mobility The Rise of a New Mode of Transportation. Technical Report. 2018. Available online: https:/ /www.readkong.com/page/urban-air-mobility-the-rise-of-anew-mode-of-transportation-7028609 (accessed on 20 July 2021).

19. Hamilton, B.A. Urban Air Mobility (UAM) Market Study. Technical Report, National Aeronautics and Space. 2018. Available online: https:/ / www.nasa.gov / sites/default/files/atoms/files/uam-market-study-executive-summary-v2.pdf (accessed on 20 July 2021).

20. Dunn, N. Analysis of Urban Air Transportation Operational Constraints and Customer Value Attributes. 2018. Available online: https:/ / dspace.mit.edu/handle/1721.1/117987 (accessed on 20 July 2021).

21. Straubinger, A.; Rothfeld, R.; Shamiyeh, M.; Büchter, K.D.; Kaiser, J.; Plötner, K.O. An overview of current research and developments in urban air mobility—Setting the scene for UAM introduction. J. Air Transp. Manag. 2020, 87, 101852. [CrossRef]

22. Kellermann, R.; Biehle, T.; Fischer, L. Drones for parcel and passenger transportation: A literature review. Transp. Res. Interdiscip. Perspect. 2020, 4, 100088. [CrossRef]

23. Lineberger, R.; Hussain, A.; Mehra, S.; Pankratz, D. Elevating the Future of Mobility. 2018. Available online: https://www2 .deloitte.com/content/dam/Deloitte/nl/Documents/consumer-business/deloitte-nl-cip-elevating-the-future-of-mobility.pdf (accessed on 20 July 2021).

24. Eißfeldt, H. Sustainable Urban Air Mobility Supported with Participatory Noise Sensing. Sustainability 2020, 12, 3320. [CrossRef]

25. Porsche Consulting. The Future of Vertical Mobility. 2018. Available online: https://www.porsche-consulting.com/fileadmin/ docs/04_Medien/Publikationen/TT1371_The_Future_of_Vertical_Mobility/The_Future_of_Vertical_Mobility_A_Porsche_ Consulting_study_C_2018.pdf (accessed on 20 July 2021).

26. Antcliff, K.R.; Moore, M.D.; Goodrich, K.H. Silicon Valley as an Early Adopter for On-Demand Civil VTOL Operations. In Proceedings of the 16th AIAA Aviation Technology, Integration, and Operations Conference, Washington, DC, USA, 13-17 June 2016. Available online: https:/ / ntrs.nasa.gov/citations/20160010150 (accessed on 20 July 2021).

27. The Future of Transportation: White Paper on Urban Air Mobility Systems. Technical Report. 2020. Available online: https:/ / www.ehang.com/app/en/EHang\%20White\%20Paper\%20on\%20Urban\%20Air\%20Mobility\%20Systems.pdf (accessed on 20 July 2021). 
28. Boelens, J.H. Pioneering the Urban Air Taxi Revolution. Technical Report, Volocopter. 2019. Available online: https: / / www.volocopter.com/content/uploads/Volocopter-WhitePaper-1-01.pdf (accessed on 20 July 2021).

29. Katrakazas, C.; Theofilatos, A.; Papastefanatos, G.; Härri, J.; Antoniou, C. Cyber security and its impact on CAV safety: Overview, policy needs and challenges. In Policy Implications of Autonomous Vehicles; Elsevier: Amsterdam, The Netherlands, 2020; pp. 7394. Available online: https://www.sciencedirect.com/science/article/abs/pii/S254300092030010X?via\%3Dihub (accessed on 20 July 2021).

30. Liimatainen, H.; Kallionpää, E.; Pöllänen, M.; Stenholm, P.; Tapio, P.; McKinnon, A. Decarbonizing road freight in the futureDetailed scenarios of the carbon emissions of Finnish road freight transport in 2030 using a Delphi method approach. Technol. Forecast. Soc. Chang. 2014, 81, 177-191. [CrossRef]

31. Jittrapirom, P.; Marchau, V.; van der Heijden, R.; Meurs, H. Future implementation of mobility as a service (MaaS): Results of an international Delphi study. Travel Behav. Soc. 2020, 21, 281-294. [CrossRef]

32. Rowe, G.; Wright, G.; Bolger, F. Delphi: A reevaluation of research and theory. Technol. Forecast. Soc. Chang. 1991, 39, $235-251$. [CrossRef]

33. Hasson, F.; Keeney, S.; McKenna, H. Research guidelines for the Delphi survey technique. J. Adv. Nurs. 2000, 32, 1008-1015. [PubMed]

34. Likert, R. A Technique for the Measurement of Attitudes. Arch. Psychol. 1932, 22, 1-55.

35. Lhoussaine, O.; Mostapha, A. Analysing Supply Chain Risk Factors: A Probability-Impact Matrix Applied to Pharmaceutical Industry. J. Logist. Manag. 2013, 2, 35-40.

36. Vegh, J.M.; Botero, E.; Clark, M.; Smart, J.; Alonso, J.J. Current Capabilities and Challenges of NDARC and SUAVE for eVTOL Aircraft Design and Analysis. In Proceedings of the 2019 AIAA/IEEE Electric Aircraft Technologies Symposium (EATS), Indianapolis, IN, USA, 22-24 August 2019; pp. 1-19. [CrossRef]

37. Chancey, E.T.; Politowicz, M.S. Public Trust and Acceptance for Concepts of Remotely Operated Urban Air Mobility Transportation. Proc. Hum. Factors Ergon. Soc. Annu. Meet. 2020, 64, 1044-1048. [CrossRef] 